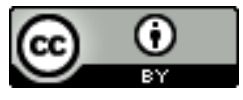

\title{
CONDICIONANTES SOCIAIS, LÓGICA DAS PRÁTICAS E ELEMENTOS CONSTITUTIVOS DO HABITUS ACADÊMICO-CIENTÍFICO DO ESTUDANTE DA PÓS-GRADUAÇÃo
}

\author{
SOCIAL CONDITIONERS, LOGIC OF PRACTICES AND CONSTITUTIVE ELEMENTS OF \\ THE ACADEMIC-SCIENTIFIC HABITUS OF THE POSTGRADUATE STUDENT \\ CONDICIONANTES SOCIALES, LÓGICA DE LAS PRÁCTICAS Y ELEMENTOS \\ CONSTITUTIVOS DEL HABITUS ACADÉMICO-CIENTÍFICO \\ DEL ESTUDIANTE DE LA POST-GRADUACIÓN
}

\section{Maísa Aparecida de Oliveira ${ }^{i}$ Maria Cristina da Silveira Galan Fernandes}

\begin{abstract}
RESUMO: O artigo busca compreender a atuação do estudante da pós-graduação, tendo como foco o desenvolvimento de elementos constitutivos do habitus acadêmico-científico. A pesquisa apresentou natureza quali-quantitativa e foi realizada em duas universidades públicas. Os participantes da pesquisa responderam um questionário on-line e uma entrevista semiestruturada. $\mathrm{O}$ estudo se fundamenta em Bourdieu. Foram utilizados, particularmente, os conceitos de campo científico, habitus e capital cultural elaborados pelo autor. Elementos da origem cultural e social dos agentes são evidenciados em suas trajetórias escolares, ações, estratégias e posições hierárquicas estabelecidas no campo da pós-graduação. A concepção da educação como possibilidade de ascensão e manutenção social está presente no ideário das famílias. Os estudantes pertencentes às classes desprivilegiadas culturalmente se esforçaram para se adequarem ao capital cultural e escolar dominantes. Os estudantes que possuem privilégios sociais utilizam o capital cultural incorporado por suas famílias como estratégia para manutenção no campo. Os resultados indicam a construção de uma nova configuração cultural no âmbito universitário em que o processo de construção do habitus do estudante é mediado pelas múltiplas relações sociais e institucionais estabelecidas no campo acadêmico-científico, trazendo, assim, implicações na socialização dos estudantes.
\end{abstract}

PAlavraS-Chave: Estudante da pós-graduação. Habitus. Campo científico. Produção de conhecimento.

\begin{abstract}
The article tries to understand the the performance of the graduate student, focusing on the development of constituent elements of the academic-scientific habitus. The research presented qualitativequantitative approach and was carried out in two public universities. The participants interviewed in the research answered an online questionnaire and a semi-structured interview. The study is based on Bourdieu. The concepts of scientific field, habitus and cultural capital elaborated by the author were used. Elements of the cultural and social origin of the graduate student are evidenced in their school trajectories, actions, strategies and hierarchical positions established in the field of post-graduation. The conception of education as a possibility of social ascension and maintenance is present in the ideals of their families. Students belonging to the culturally underprivileged classes struggled to fit to the dominants capital cultural and school. Students who have social privileges use the cultural capital incorporated by their families as a strategy for maintenance in the field. The results indicate the construction of a new cultural configuration in the university context in which the process of student habitus construction is mediated by the multiple social and institutional relations established in the academic-scientific field, thus bringing implications to the students' socialization.
\end{abstract}

Submetido em: 20/06/2017 - Aceito em: 10/07/2017 - Publicado em: 12/09/2017.

n.3

$478-493$

set./dez. 2017 
KEYWORDS: Graduate student. Habitus. Scientific field. Knowledge Production.

RESUMEN: El artículo busca comprender la actuación del estudiante del postgrado, teniendo como foco el desarrollo de elementos constitutivos del habitus académico-científico. La investigación he apresentado una naturaleza cualitativa y se realizó en dos universidades públicas. Los participantes de la encuesta respondieron un cuestionario en línea y una entrevista semiestructurada. El estudio se fundamenta en Bourdieu. Se utilizaron, en particular, los conceptos de campo científico, habitus y capital cultural elaborados por el autor. Los elementos del origen cultural y social de los agentes son evidenciados en sus trayectorias escolares, acciones, estrategias y posiciones jerárquicas establecidas en el campo del postgrado. La concepción de la educación como posibilidad de ascenso y mantenimiento social está presente en el ideario de las familias. Los estudiantes pertenecientes a las clases desprivilegiadas culturalmente se esforzaron para adecuarse al capital cultural y escolar dominantes. Los estudiantes que poseen privilegios sociales utilizan el capital cultural incorporado por sus familias como estrategia para el mantenimiento en el campo. Los resultados indican la construcción de una nueva configuración cultural en el ámbito universitario en que el proceso de construcción del habitus del estudiante es mediado por las múltiples relaciones sociales e institucionales establecidas en el campo académico-científico, trayendo, así, implicaciones en la socialización de los estudiantes.

PALABRAS ClAvE: Estudiante de postgrado. Habitus. Campo científico. Producción de conocimiento.

\section{INTRODUÇÃo}

A temática deste artigo se insere no âmbito de pesquisas sobre o estudante do ensino superior público. Entendemos que a formação de estudantes universitários para a cidadania e para o mundo do trabalho necessita de critérios de qualidade compatíveis com as exigências estabelecidas pelo campo acadêmico em articulação com as necessidades sociais. Especificamente, a pós-graduação tem como finalidade a formação e o desenvolvimento da pesquisa, revestida de pertinência social e científica.

Nesse sentido, consideramos como eixo de análise a atuação do estudante da pós-graduação, tendo como foco de estudo o desenvolvimento de elementos constitutivos do habitus acadêmico-científico do estudante da pós-graduação, a partir da análise do capital cultural e familiar no processo de socialização, na trajetória escolar e nas relações familiares do pósgraduando. Problematizamos, assim, as implicações de tais processos na atuação do estudante no decurso da pós-graduação.

Nossas reflexões constituem um recorte da pesquisa de doutoramento que teve como objeto de investigação o produtivismo acadêmico, tendo como foco de análise a formação do estudante da pós-graduação e o processo de produção do conhecimento, analisando as condições e estratégias utilizadas pelo estudante para se manter no campo acadêmicocientífico. 
A pesquisa apresentou natureza quali-quantitativa e foi realizada em duas Instituições Federais de Ensino Superior (IFES) localizadas na Região Sudeste do Brasil ${ }^{2}$. A amostra de participantes foi composta por 239 pós-graduandos que responderam um questionário on-line encaminhado a todos os mestrandos e doutorandos do programa de pós-graduação (PPG) mais conceituado, de acordo com a avaliação da CAPES, em cada Centro de Ciências relacionado às grandes áreas Humanas, Biológicas, Exatas e Agrárias das IFES pesquisadas. Posteriormente realizamos entrevista individual, semiestruturada com 14 estudantes (sete mestrandos e sete doutorandos) que responderam ao questionário on-line. A participação dos estudantes foi voluntária e não houve qualquer parcialidade na obtenção dos dados ${ }^{3}$.

Em uma breve caracterização dos participantes da pesquisa, evidenciamos que a amostra dos participantes foi constituída de 142 estudantes matriculados no Doutorado e 97 estudantes do Mestrado, perfazendo um total de 239 pós-graduandos. A média das idades dos participantes da pesquisa foi de 29,59 anos. Identificamos que há maior participação de estudantes mulheres na pós-graduação, representando $66,4 \%$ da amostra. A maior incidência de mulheres na pós-graduação corrobora a informação de que o crescimento do número de mulheres tituladas no Brasil supera a titulação dos homens desde 2004 (CENTRO DE GESTÃO E ESTUDOS ESTRATÉGICOS, 2010).

\section{A ATUAÇÃo do ESTUDANTE dA PÓS-GRADUAÇÃo À LUZ DA TEORIA DE PIERRE BOURDIEU: AS INTER-RELAÇÕES SOCIAIS E A INSERÇÃO NO CAMPO ACADÊMICO-CIENTÍFICO}

Com base no referencial teórico deste trabalho, compreendemos que as concepções de campo, habitus e capital cultural, elaboradas pelo sociólogo Pierre Bourdieu nos apresentam reflexões importantes sobre as relações que o estudante da pós-graduação estabelece no campo acadêmico-científico, numa disputa de posição que este agente assume nos espaços sociais.

Em linhas gerais, o conceito de campo elaborado por Bourdieu (1983) traz como referência espaços de disposições sociais, de dominação e de lutas, em que cada espaço social (campo) possui suas próprias regras de organização e hierarquia social, bem como de certa autonomia. $\mathrm{O}$ conceito de habitus consiste na maneira como os agentes se portam e agem nas estruturas sociais; é um sistema de disposições do indivíduo que condiciona diretamente as ações do

\footnotetext{
${ }^{2}$ As instituições serão identificadas no decorrer do artigo pelos seguintes códigos: IFES1 e IFES2.

${ }^{3}$ Convidamos diversos estudantes, aleatoriamente, para a entrevista considerando que nossa amostra deveria ser de um estudante de cada curso de mestrado e um do doutorado, totalizando 14 estudantes.
}

n.3

$478-493$

set./dez. 2017 
estudante da pós-graduação no campo acadêmico-científico. O habitus é incorporado nas relações estabelecidas socialmente, caracterizadas nas predileções e nas aptidões dos indivíduos (NOGUEIRA; NOGUEIRA, 2002).

Nessa perspectiva, elementos da origem cultural e social dos agentes são evidenciados em suas trajetórias escolares, ações, estratégias e posições hierárquicas estabelecidas no campo da pós-graduação.

Nesse contexto, Bourdieu (2013b, p. 87) delineia o conceito de habitus a partir da análise dos condicionamentos adjuntos de uma classe específica de condições de existência que, para o autor, produzem habitus, ou seja, "sistema de disposições duráveis e transponíveis, estruturas estruturadas predispostas a funcionar como estruturas estruturantes" que atuam como prelúdio (origem) de indução e sistematização de práticas e representações que objetivamente podem ser apropriadas à sua finalidade, sendo instrumentalizada pelo grupo de pertença e isenta do produto da ação estruturada por um regente.

Bourdieu (2013b, p. 89) analisa a relação que existe nas "probabilidades objetivas" cientificamente elaboradas, como as possibilidades de aquisição de determinado bem, e as "esperanças subjetivas", entendidas como as "motivações e necessidades". Segundo Bourdieu (2013b) os agentes não necessariamente adaptam seus anseios de maneira consciente às suas possibilidades de êxito, tendo em vista que as disposições duráveis inculcadas pelas chances de sucessos ou insucessos, necessidades e liberdades que estão imbuídas nas condições objetivas projetam disposições objetivamente conciliáveis com tais disposições que, de certa maneira, estão adequadas às demandas, tendendo a negar o que seria fracasso e a almejar o que já está dado.

Ressalta-se que a temática desta pesquisa está inserida nas discussões realizadas no campo da Sociologia da Educação ao buscar compreender o ingresso e a atuação do estudante no ensino superior, especificamente, sua inserção na pós-graduação. Consideramos que existe carência de estudos centrados no estudante da pós-graduação no campo da Sociologia da Educação, o que confere originalidade a este artigo. Além disso, a temática proposta contribui para a reflexão e ampliação de políticas e projetos universitários que auxiliem no processo de inserção, adaptação e permanência do estudante na pós-graduação.

\footnotetext{
As próprias condições de produção do habitus, necessidade feita virtude, fazem com que as antecipações que ele engendra tendam a ignorar a restrição à qual está subordinada a validade de todo cálculo das probabilidades, a saber, que as condições da experiência não tenham sido modificas (...) as antecipações do habitus, espécie de hipóteses práticas fundadas na experiência passada, atribuem um peso desmedido às primeiras experiências (BOURDIEU, 2013b, p. 89).
}

Consideramos, fundamentadas em Setton (2002), que o processo de constituição do habitus individual é mediado por instâncias que caracterizam valores culturais e referências 
identitárias, em uma relação que ocorre de maneira dinâmica e permanente. Tal relação não precisa ser constituída de maneira linear, tendo em vista que o processo de socialização ocorre fundamentado em múltiplas relações sociais que podem ser estabelecidas entre aliados e concorrentes ou de ruptura e assiduidade.

De acordo com Pierre Bourdieu, pela cultura escolar, o sistema de ensino revela um modus operandi no qual os sujeitos se relacionam e se comunicam, compartilhando uma cultura de classe que se fundamenta em determinados modos de agir e pensar que identificam os grupos como iguais. Bourdieu e Passeron (1975) expõem que o sistema de ensino materializado nas instituições escolares se tornou um instrumento dócil de reprodução social em que se confrontam interesses antagônicos, mas legitimam os interesses das classes dominantes. Para tal, utilizam-se instrumentos pedagógicos para reproduzir as estruturas das classes.

Segundo Bourdieu (2013a), enquanto sistema regente no ensino superior e na pós-graduação, a universidade se destina a reproduzir características sociais e escolares que são, em tese, homogêneas e constantes.

Assim, a escolha da teoria elaborada por Pierre Bourdieu como referencial teórico deste artigo decorreu da compreensão de que o autor produziu uma sociologia crítica que nos possibilita perceber as diversas relações que o estudante da pós-graduação estabelece na universidade, no que se refere à cultura, ciência, produção de conhecimento, especialmente na pós-graduação, e à reprodução social.

\section{PROCESSO FORMATIVO, SOCIALIZAÇÃo, CAPITAL CULTURAL E FAMILIAR DOS ESTUDANTES DA PÓS-GRADUAÇÃO: DESDOBRAMENTOS NA CONSTRUÇÃO DO HABITUS ACADÊMICO}

Com base nas reflexões anteriores, o importante papel da instituição escolar na vida dos agentes sociais, de acordo com Bourdieu (2015a), está condicionado às deliberações das transmissões da herança familiar. Assim, possíveis transformações nas disposições dos sujeitos refletem intensamente sobre as identidades individuais ou, em outras palavras, incidem diretamente no habitus do indivíduo (BOURDIEU, 2015c).

De acordo com Bourdieu (2015a), os estudantes oriundos de famílias privilegiadas culturalmente apresentam uma relação com as obras de cultura difundidas pela instituição escolar que tendencialmente são interessadas, habilidosas, diletantes e processualmente naturais. Ao passo que, para os estudantes desfavorecidos de capital cultural, tal relação escolar tende a ser trabalhosa, tensa, esforçada e ocorre em um processo forçado/imposto. 
Em nossa pesquisa, os seis estudantes da pós-graduação da IFES1 afirmaram que foram estudiosos desde o início da escolarização. A maior parte deles (representando $66,7 \%$ da amostra) estudou em escolas particulares na educação básica. O processo de escolarização para os estudantes pesquisados na IFES1 representou uma continuidade do processo de interação social vivenciado no meio familiar, uma vez que a maior parte dos pais dos estudantes da IFES1 possui níveis de escolarização elevados, transmitindo conhecimentos, vivências e experiências legitimados pela instituição escolar, o que foi benéfico para o processo de escolarização de tais estudantes.

Dentre os oito estudantes entrevistados na IFES2, quatro pós-graduandos relataram que tiveram um processo de escolarização conturbado, sobretudo nos anos iniciais. A estudante do doutorado pertencente à área de Agrárias afirmou que frequentou diversas escolas em cidades e países distintos, o que dificultou o processo de aprendizagem e adaptação.

Outros três estudantes da IFES2 tiveram dificuldades de acesso à escola, precisaram mudar de cidade para estudar e trabalhar ou, quando crianças, moraram de favor em residências de amigos das famílias, além de estudarem em salas multisseriadas. Distintivamente, a estudante do mestrado pertencente à área de Agrárias cursou a Educação Básica em escolas particulares e não descreveu qualquer dificuldade no processo de escolarização, o que, com base em Bourdieu (2015c) pode ser entendido como continuidade do processo de socialização familiar. Os demais pós-graduandos da IFES2 relataram que conseguiram acompanhar o processo de ensino e aprendizagem com certa facilidade e que no período de transição entre as escolas públicas e privadas tiveram menor desempenho acadêmico.

As estudantes da IFES1 do Centro de Ciências relacionado às áreas de Humanidades afirmaram que tiveram dificuldade com os conteúdos das disciplinas de matemática, física e química no decurso da educação básica e utilizaram estratégias para sanarem suas dificuldades e a escolha por cursos de graduação em áreas de maior domínio e afinidade.

Já os estudantes das áreas das Exatas e Biológicas disseram que não tinham dificuldades nas disciplinas, apresentando maior facilidade, inclusive, em literatura, sociologia e história. Para esses estudantes o processo de escolarização ocorreu de maneira processual e "naturalizada", sem que houvesse grandes dificuldades que causassem transtornos em relação ao capital cultural herdado da família, o que pode ser relacionado com o sucesso obtido no mercado escolar. Nesse sentido, podemos considerar que o nível sociocultural de tais estudantes pode estar relacionado ao êxito escolar e à continuidade da trajetória escolar nos estudos pósgraduados (OLIVEIRA; MELO-SILVA, 2010).

O processo de escolarização de quatro estudantes da IFES2 relacionado aos Centros de Ciências Humanas, Agrárias e Exatas ocorreu de maneira similar ao processo vivenciado pelos participantes da IFES1. O processo de escolarização vivenciado por três estudantes da

\begin{tabular}{l|l|l|l|l|l} 
(c) Rev. Inter. Educ. Sup. & Campinas, SP & v.3 & n.3 & $478-493$ & set./dez. 2017 \\
\hline
\end{tabular}


IFES2, diante das adversidades enfrentadas apresentou grande avanço nas perspectivas sociais e acadêmicas dos estudantes, rompendo a ordem social estabelecida para tais agentes sociais. A estudante do mestrado pertencente à área de Humanas da IFES2 afirmou: "eu sou uma sobrevivente do sistema, porque ele me jogou a vida toda para o escanteio". Tal estudante finalizou o Ensino Médio na modalidade de Educação de Jovens e Adultos, após vários anos trabalhando no comércio e, após diversas tentativas em vestibulares, ingressou no Ensino Superior.

De acordo com Bourdieu e Passeron (1975), a seleção dos estudantes ocorre a partir de critérios como a origem social, o sexo, além do capital escolar e cultural dos familiares. A eliminação (ou, ainda, seleção) ocorre de maneira distinta entre os sujeitos, a depender de suas características ou categorias hierárquicas. Segundo o autor, os estudantes das classes populares e médias que conseguem ingressar no Ensino Superior sofrem a mais forte seleção, o que corrobora o sentimento da referida estudante de que o sistema sempre tentou jogá-la para fora do jogo.

[...] numa população que é o produto da seleção, a desigualdade da seleção tende a reduzir progressivamente e às vezes a anular os efeitos da desigualdade ante a seleção diferencial: de fato, só a seleção diferencial segundo a origem social e, em particular, a superseleção dos estudantes de origem popular permitem explicar sistematicamente todas as variações da competência lingüística em função da classe social de origem e, em particular, a anulação ou a inversão da relação direta (observável em níveis menos elevados do curso) entre a possessão de um capital cultural (determinado pela profissão do pai) e o grau de êxito (BOURDIEU; PASSERON, 1975, p. 97).

Podemos considerar que a desigualdade social se concretiza na desistência ou no fracasso do estudante ou, de maneira antagônica, na capacidade de prosseguir e ultrapassar as barreiras "do sistema", tendo como pano de fundo o sonho a ser conquistado, construído outrora sob a concepção de que é possível alcançar o sucesso escolar, como foram direcionados, especialmente, os estudantes oriundos de camadas populares da IFES2.

A maioria dos pós-graduandos das IFES pesquisadas relatou que não tinham o costume de frequentar cinemas, museus e teatros e justificaram que a oportunidade de participar de tais atividades na maioria das cidades brasileiras é restrita. Entretanto, uma participante do mestrado pertencente à área de Humanas da IFES1 e uma estudante do mestrado pertencente à área de Agrárias da IFES2 afirmaram que participavam com frequência de atividades culturais. Ressaltamos que o pai da estudante da IFES1 é juiz federal e professor universitário e sempre influenciou e ratificou a importância de que ela e os irmãos participassem de tais atividades, assim como a mãe que é professora da educação básica e ambos tiveram um papel determinante na escolarização da participante da pesquisa, além de residir durante a infância em uma cidade privilegiada culturalmente. 
Embasando-se em Bourdieu, Setton (2010, p. 27) considera que o "domínio da cultura erudita, o tipo de aprendizado, ainda que muitas vezes processado de maneira difusa pela família, deveria ser complementado pelo trabalho metódico da escola". Consideramos, com base em Bourdieu (2007), que o gosto por práticas culturais (legitimadas ou não) pode se constituir como produto de um processo educativo e da ambientação familiar, ou seja, não representa uma aptidão inata dos indivíduos e sim uma construção das relações interpessoais vivenciadas pelos estudantes da pós-graduação.

Os depoentes também afirmaram que sempre leram muito, ainda que fossem leituras consideradas "bobinhas" pelos entrevistados, como ficção, fantasia, romance, entre outros gêneros literários. Podemos compreender como boa vontade cultural a adaptação ou a aproximação feita pelos sujeitos das classes médias e populares da cultura erudita, o que diminuiria possíveis desvantagens na aquisição da cultura dominante (NOGUEIRA, 1997). Identificamos no hábito de leitura a boa vontade cultural, em que os estudantes da pósgraduação se aproximam da linguagem da norma culta. Para Oliveira (1996), o interesse e a abertura para a compreensão do texto possibilitam a reformulação ou adaptação do conhecimento trazido pelo indivíduo para a incorporação de novas experiências, informações e conhecimentos. Assim, o capital cultural incorporado foi acumulado, por meio das leituras, disposições duráveis aos organismos dos agentes e demandou tempo (processo que perdurou durante toda a educação básica dos estudantes entrevistados), o que implica em um trabalho de inculcação e assimilação, investidos pelo próprio agente (BOURDIEU, 2015e). Tal escopo tende a determinar as ações futuras dos agentes, como por exemplo, cursar o ensino superior e prosseguir na carreira acadêmica.

Refletindo sobre o contexto sócio-histórico amplo, a escolha pelos cursos superiores, bem como as possibilidades de ingresso e a permanência na universidade são influenciadas pela procedência escolar (OLIVEIRA; MELO-SILVA, 2010). A estudante do doutorado pertencente à área de Biológicas da IFES1 estudou em escolas públicas durante todo o processo de escolarização e realizou dois anos de curso pré-vestibular, justificado por pretender cursar Medicina. No entanto, a estudante recalculou as reais possibilidades de ingressar no curso de Medicina e escolheu outro curso de graduação (Fisioterapia) considerado "mais fácil".

Nesse sentido, observamos que diferenças sociais são transformadas pelo sistema de ensino em desigualdades do destino escolar como produto da herança econômica e cultural familiar, ao passo que a escola, com base em Bourdieu e Passeron (1975), atua reproduzindo a cultura e a conservação social. Apesar do valor e prestígio do curso de Fisioterapia na sociedade, ainda é visível a existência da distinção das credenciais escolares obtidas em cursos de Medicina (BOURDIEU, 2015d). Consideramos, portanto, que a escola legitima a cultura das classes economicamente privilegiadas ao reproduzir as diferenças das classes sociais. Assim,

\begin{tabular}{|l|c|c|c|c|c|}
\hline C Rev. Inter. Educ. Sup. & Campinas, SP & v.3 & n.3 & $478-493$ & set./dez. 2017 \\
\hline
\end{tabular}


o acesso a essas instituições, ou, de maneira específica, aos cursos privilegiados social e economicamente se torna limitado para as classes populares (BOURDIEU, 2015a).

No campo social, o sujeito ou seu grupo social adquirem uma posição de vantagem ou desvantagem a partir do volume, da composição e da incorporação de um ou mais capitais (seja ele: simbólico, econômico ou cultural) no decorrer de sua trajetória social. Os estudantes entrevistados matriculados na pós-graduação da IFES1 demonstraram possuir algum tipo de capital, seja o econômico, o social, simbólico e/ou cultural. Tais trajetórias evidenciam o papel da instituição escolar de conservação e reprodução da sociedade, o que mantêm os benefícios de classes sociais privilegiadas.

Desta maneira, podemos considerar que os estudantes da pós-graduação da IFES2 que cursaram o Ensino Básico integralmente em escolas públicas, que desempenharam grandes esforços em salas multisseriadas, residindo com "pessoas amigas da família" para estudar e conciliando trabalho e estudos, trilharam uma trajetória alternativa contra a reprodução social.

Para Vianna (2000) o estudante pode desenvolver uma capacidade específica e ativa no processo de escolarização que se direciona em uma trajetória de sucesso escolar. Nesse sentido, o estudante demonstra um investimento pessoal em sua escolarização, bem como uma autodeterminação, conforme narrado pelo estudante do mestrado pertencente à área de Agrárias da IFES1 que, no decurso da graduação, foi beneficiado pelo Programa Ciência Sem Fronteiras e fez estágio em um país de língua inglesa com o aprendizado de língua obtido na Educação Básica que, segundo o estudante, foi precário. Podemos considerar, com base em Viana (2000), que tal capacidade ativa e de determinação pode ter sido instigada e construída no contexto familiar, no entanto, foi possível perceber nas falas dos participantes da pesquisa que as mobilizações pessoais foram próprias dos estudantes, especialmente, oriundos da escola pública que desempenharam maior esforço acadêmico, tendo em vista a distância existente entre as famílias das classes desprivilegiadas/escolas públicas e as classes/sistemas de ensino superior elitizados.

De acordo com Lahire (1997), os pais que depositam elevadas expectativas sobre a escolarização dos filhos podem controlar o processo escolar ao acompanhar em detalhes as atividades, ao corrigir e supervisionar os trabalhos tanto dos filhos quanto dos professores, externando o grau de satisfação para com os mesmos, dentre outros dispositivos de controle do processo escolar. No entanto, o autor considera ainda que a rentabilidade escolar varia de acordo com a configuração familiar, podendo produzir efeitos positivos (a partir de um pequeno capital escolar) ou desencadear efeitos negativos na escolarização dos filhos (mesmo com elevado controle sobre a escolarização dos filhos e capital cultural privilegiado).

Sobre o incentivo da família aos estudos, os participantes da pesquisa da IFES1 relataram que desde o início do processo de escolarização foram incentivados pelos pais. Tal incentivo foi 
percebido de diferentes maneiras. O estudante de mestrado pertencente à área de Exatas afirmou, por exemplo, que os pais queriam que os filhos estudassem e diziam: "Vai ficar aqui (cidade de origem) e trabalhar com o pai (pedreiro) ou vai estudar? Eu acho melhor você estudar'. Desde pequeno eu tinha isso na cabeça. Era uma cobrança tranquila; eles não cobravam que eu deveria ser o melhor".

Para Lahire (1997) os pais externam o desejo em relação ao futuro profissional dos filhos e, concomitantemente, desqualificam-se profissionalmente quando "almejam para sua progênie um trabalho menos cansativo, menos sujo, menos mal-remunerado, mais valorizado do que o deles" (LAHIRE, 1997, p. 334).

Os estudantes da IFES2 participantes da pesquisa relataram que os pais que incentivaram os filhos a estudarem o faziam por meio de incentivo financeiro (representando $62,5 \%$ da amostra) e orientação direcionada à necessidade dos estudos para a ascensão ou manutenção social. Foi relatado pelos estudantes que os pais não ajudavam nas dificuldades e no cotidiano escolar, apenas cobravam por bons resultados e por disciplina. O limite ou o "bom comportamento" estabelecido na rotina escolar é considerado importante para a internalização da submissão à autoridade escolar e bom desempenho nas atividades de ensino e aprendizagem (LAHIRE, 1997).

Conforme apontam Bourdieu e Passeron (2014), o acesso ao ensino superior e, especificamente, o prolongamento da escolarização dos indivíduos que escolhem (e, de certa maneira, são escolhidos pelo habitus que detém) está relacionado à origem social dos indivíduos, conservando e reproduzindo a hierarquia social, tendo em vista que:

As oportunidades objetivas de cada grupo social condicionam a experiência dos atores, configuram suas esperanças subjetivas e suas escolhas concretas, fazendo com que os mesmos contribuam, sem que tenham plena consciência disso, para a realização de uma trajetória escolar e social bastante próxima ao que seria objetivamente (estatisticamente) mais provável para indivíduos com seu perfil social (NOGUEIRA; NOGUEIRA, 2015, p. 52).

Com base em Bourdieu (2015a) entendemos que o investimento intelectual dos agentes propiciado pelos familiares ou pelo próprio agente, ocorre consciente ou inconscientemente mediado pelas estruturas de oportunidades de lucro material e simbólico da educação. Pela ênfase dada pela estudante do doutorado pertencente à área Biológica da IFES1, podemos inferir que o trabalho para a família da estudante era fundamental, mas por acreditar que a educação (o curso superior) aumentaria as perspectivas de ascensão social, o incentivo da mãe foi dado pelo benefício de não trabalhar no decurso da graduação, ainda que a estudante tenha recebido bolsa de Iniciação Científica neste período.

Segundo Bourdieu (2006), as famílias das classes médias investem mais na educação escolar dos filhos amparadas pela ideia de que a escola amplia a possibilidade de ascensão social e, 
para tal, esforçam-se, renunciando a prazeres imediatos, em benefício de projetos futuros. Assim, tais famílias passam a reconhecer como legítima a cultura oferecida na escola, esforçando-se, sistematicamente, para adquiri-la. Tal estratégia de investimento familiar pode ser ratificada ao analisarmos a prioridade da família da estudante do doutorado pertencente à área de Humanas da IFES1, que contratou professores particulares para reduzir as dificuldades escolares da filha, deixando de realizar outras atividades ou necessidades familiares.

O incentivo familiar que o estudante do doutorado pertencente ao Centro de Ciências Exatas da IFES1 obteve dos pais (detentores de elevados níveis de escolarização) para o ingresso no ensino superior pode ser percebido na seguinte fala: "O incentivo às Ciências Exatas nunca foi o foco da minha família, queriam que eu tivesse uma profissão que desse dinheiro". Consideramos relevante abordar como a influência das famílias afeta a vida dos filhos, o estudante continuou relatando: "Eu tive que fazer um ano de Agronomia, onde eu sofri bulliyng. Foi um ano completamente desperdiçado da minha vida, nem na Física, nem nas disciplinas de Cálculo eu conseguia ir bem, simplesmente eu não conseguia estudar”.

Embasados em Lahire (1997) compreendemos que a influência dos pais ou grupos de referência pode impactar positiva ou negativamente na vida do indivíduo. O doutorando descreveu uma experiência de insucesso, embora os pais tenham mudado a postura para com o filho após, de certa maneira, imporem a realização de um curso superior que "desse dinheiro". A lógica das práticas é inerente às ações e ao sentido objetivo das vivências dos agentes investigados e, raramente, escapam a subjetividade das aspirações e projetos individuais, como observado na experiência de realizar um curso para responder às aspirações familiares.

Há relatos também de influências que geraram experiências positivas na escolarização dos participantes da pesquisa, como indicado pela estudante do mestrado pertencente à área Biológica da IFES1 que considerou a vivência da irmã mais velha na pós-graduação determinante para que ela pudesse continuar na carreira acadêmica. Assim, ressaltamos que a lógica das práticas atua de maneira indireta, na incorporação "natural" de um habitus por interesse do próprio sujeito.

Além disso, alguns estudantes participantes da pesquisa na IFES2 afirmaram que são os únicos na família que cursaram o ensino superior em universidades públicas e, ainda, continuaram na carreira acadêmica, o que os tornou referência para familiares em geral e amigos próximos, conforme evidencia a estudante matriculada no doutorado do Centro de Ciências Agrárias: 
O mais importante também é o que represento para a minha nova geração, para meus sobrinhos. Faço a diferença para eles hoje. Eles falam que não gostam de estudar, mas estudam, esforçam-se para ser igual à tia, para conhecer o mundo como a tia conhece. Eu me sinto muito orgulhosa disso.

A escolha por uma prática ou, especificamente, o gosto pelos estudos não são neutros ou naturais. Como produto de uma história social, o desejo de "conhecer o mundo como a tia conhece" traduz o reconhecimento da estrutura social vivenciada pelos sobrinhos e o desejo de romper com o mundo experienciado. A diferença existente entre os estilos de vida, ou ethos, revelam a hierarquização e a separação entre duas realidades ou grupos que possuem distintos capitais culturais e escolares: o pai que não estudou e a tia que conhece outro mundo. Para Bourdieu (2015c) a identificação com um projeto de sucesso escolar, familiar neste caso, ou de um grupo de referência, compõe a condição necessária à "transmissão" da herança de capital cultural, social ou escolar, materializada na herança paterna rejeitada.

A estrutura social, ou o sistema de posições sociais, supõe propriedades de posição e as condições materiais de existência dos sujeitos sociais. Os estudantes entrevistados da IFES1, afirmaram que os pais possuem reconhecimentos e prestígios sociais e profissionais, ainda que de maneira moderada em alguns casos (por exemplo, o pai que atua como pedreiro ou aqueles que são funcionários públicos). Refletindo sobre o capital econômico, segundo os participantes, os pais possuem uma estabilidade econômica média a uma situação econômica privilegiada. Verificamos certa linearidade entre os reconhecimentos profissionais, sociais e econômicos. Foi possível inferir, por exemplo, que os pais dos entrevistados da IFES1, além de possuírem, em sua maior parte, níveis de escolarização elevados, possuem reconhecimento e/ou prestígio, o que lhes garante uma posição na hierarquia social proeminente.

Contudo, é importante destacar, conforme indica Nogueira (1997), fundamentada em Bourdieu que a posição de classe não depende apenas do capital econômico. Para tanto, não é determinante a posição sincrônica do sujeito, mas sim a sua trajetória social a depender das frações de classe (declínio, ascensão ou estabilidade) que irá influenciar no habitus, na cultura e no ethos. Assim, a posição e o privilégio social dos pais dos participantes da pesquisa na IFES1, o capital cultural do pai e/ou da mãe de cada entrevistado atua como estratégia de socialização.

Para Bourdieu (2007), a distinção é construída a partir da naturalização dos sujeitos e dos grupos sociais da cultura legítima, em relação à posição ocupada pelos estudantes da pósgraduação no espaço social. Com base no autor compreendemos que o processo de reprodução do capital cultural está vinculado à dominação e herança sociais.

As posições de classe podem ser constatadas também pelos estudantes na IFES2. Para a estudante do doutorado relacionado à área de Agrárias, os pais não possuem reconhecimento e valorização profissionais, embora detenham situação financeira confortável. A doutoranda 
pertencente à área de Exatas da IFES2 considerou que a mãe possui uma posição social privilegiada, mas não detém reconhecimento profissional, já o pai não possui valorização e reconhecimento profissional e social. Para os demais estudantes da IFES2 os pais não possuem reconhecimento social, profissional e econômico, o que sugere que a aquisição da cultura e a ação pedagógica de tais estudantes ocorreram como um trabalho sistêmico, robusto, esforçado "que confere ao seu portador uma relação com a cultura que tende a ser mais laboriosa, interessada, forçada, tensa, insegura, em suma, mais 'militante"" (NOGUEIRA, 1997, p. 118). É preciso considerar, com base em Bourdieu (2015b), que as possibilidades de acesso ao ensino superior e, posteriormente, à pós-graduação, são rigorosamente desiguais para os sujeitos de diferentes classes e oportunidades sociais. Nesse sentido, identificamos que tais sujeitos oriundos das classes desprivilegiadas culturalmente empregaram na atividade escolar, a boa vontade cultural, esforçando-se para adaptarem-se às classes e práticas culturalmente favorecidas para a aquisição de disposições específicas exigidas pelo campo acadêmico.

A herança familiar e a boa vontade cultural influenciam no desenvolvimento do habitus acadêmico dos estudantes da pós-graduação, sejam os estudantes oriundos das classes privilegiadas ou das classes populares. Para o ingresso e manutenção no campo acadêmicocientífico os estudantes têm se empenhado com veemência para incorporar o habitus experienciado e cumprir as exigências da pós-graduação. Entretanto, tal conduta tem levado a uma intensificação das atividades e transformação da produtividade acadêmica em produtivismo.

A causalidade do provável (BOURDIEU, 2015b) representa o produto do habitus, como disposições duráveis dadas as experiências anteriores e que permitem indicar escolhas futuras, como a inserção na pós-graduação, a escolha pelo orientador e pela temática pesquisada.

Em tal perspectiva, consideramos que a atuação dos sujeitos sociais depende das possibilidades objetivas proporcionadas pelos capitais econômico, simbólico ou social, o que implica em um habitus que produza estratégias de atuação objetivas (BOURDIEU, 2015b).

Com base nos dados da pesquisa, compreendemos que o pós-graduando está desenvolvendo estratégias que estão sendo incorporadas como traços do habitus universitário. Compreendemos que o habitus é instrumentalizado na sistematização de práticas e ações que são engendradas no campo científico, bem como pelo reconhecimento e legitimidade da própria comunidade acadêmica (BOURDIEU, 2013b). A composição do habitus acadêmico do estudante vem sendo validado e perpetuado pelas proposições do campo acadêmicocientífico que predispõe as ações dos pós-graduandos. 
Diversas estratégias foram identificadas na atuação do estudante: a busca pela obtenção de capital cultural e científico, reprodução de práticas específicas do campo científico que geram lucro no mercado acadêmico e incorporação do habitus esperado pela universidade. Nessa perspectiva, observamos que as estratégias e as práticas de fazer pesquisa estão sendo intensificadas e cristalizadas em novos traços do habitus acadêmico do estudante da pósgraduação.

Conforme ratificado por Bourdieu (2013a), o pós-graduando interessado em se manter no campo acadêmico-científico almeja trabalhar no ritmo do sistema, pois acredita que precisa se adequar ou ampliar seu desempenho. Não obstante, o sistema universitário se conserva pela dependência (ou precaução) de seus agentes na subordinação e adequação às regras do campo, o que requer um habitus universitário que tende a ser reproduzido e normalizado entre os agentes. Ademais, o habitus pode ser caracterizado também como um aparelho de orientação em que ora pode ser consciente, ora pode ser inconsciente, a depender da predisposição e das condições sociais e materiais de existência e de atuação (SETTON, 2002).

\section{CONSIDERAÇÕES FINAIS}

A concepção e o discurso da educação como possibilidade de ascensão e manutenção social estão presentes no ideário das famílias. Os estudantes pertencentes às classes desprivilegiadas culturalmente se esforçaram demasiadamente para se adequarem ao capital cultural e escolar dominantes, a fim de adquirirem as disposições específicas exigidas pelo campo. Já os estudantes cujos pais possuem posição e privilégios sociais utilizam como estratégia para inserção e manutenção no campo, o capital cultural incorporado pelas famílias.

A partir dos resultados da pesquisa, inferimos que tem se constituído uma nova configuração cultural no âmbito universitário, em que o processo de construção do habitus do estudante é mediado pelas múltiplas relações sociais e institucionais estabelecidas no campo acadêmicocientífico, trazendo, assim, implicações na socialização dos estudantes. Embasando-nos em Bourdieu (2015b), apreendemos que a busca pelo reconhecimento acadêmico e social expressas na obtenção de capital cultural e científico e na reprodução da lógica existente no campo são estratégias capazes de legitimar a lógica do campo científico e naturalizá-las.

\section{REFERÊNCIAS}

BOURDIEU, Pierre; PASSERON, Jean-Claude. A reprodução. Elementos para uma teoria do sistema de ensino. Rio de Janeiro: Francisco Alves, 1975.

\begin{tabular}{|l|l|l|l|l|l|} 
(C) Rev. Inter. Educ. Sup. & Campinas, SP & v.3 & n.3 & $478-493$ & set./dez. 2017 \\
\hline
\end{tabular}


BOURDIEU, Pierre. Pierre Bourdieu: Sociologia. São Paulo: Ática, 1983.

BOURDIEU, Pierre. O poder simbólico. Rio de Janeiro: Bertrand Brasil, 2006.

BOURDIEU, Pierre. A distinção: crítica social do julgamento. São Paulo: Edusp, 2007.

BOURDIEU, Pierre. Homo academicus. Tradução: Ione Ribeiro Valle, Nilton Valle; revisão técnica Maria Tereza de Queiroz Piacentini. 2 ed. Florianópolis: Ed. Da UFSC, 2013 a.

BOURDIEU, Pierre. O senso prático. 3 ed. Petrópolis, RJ: Vozes, 2013 b.

BOURDIEU, Pierre. A Escola Conservadora: as desigualdades frente à escola e à cultura. In: NOGUEIRA, M.A.; CATANI, A. (Org.). Escritos da educação. Petrópolis, RJ: Vozes, 2015a. p. 43-72.

BOURDIEU, Pierre. Futuro de classe e causalidade do provável. In: NOGUEIRA, M.A.; CATANI, A. (Org.). Escritos da educação. Petrópolis, RJ: Vozes, 2015b. p. 89-142.

BOURDIEU, Pierre. As contradições da herança. In: NOGUEIRA, M. A.; CATANI, A. (Org.). Escritos da educação. Petrópolis, RJ: Vozes, 2015c. p. 257-266.

BOURDIEU, Pierre. O diploma e o cargo: relações entre o sistema de produção e o sistema de reprodução. In: NOGUEIRA, M.A.; CATANI, A. (Org.). Escritos da educação. Petrópolis, RJ: Vozes, 2015d. p. 143-162.

BOURDIEU, Pierre. Os três estados de capital cultural. In: NOGUEIRA, M. A.; CATANI, A. (Org.). Escritos da educação. Petrópolis, RJ: Vozes, 2015e. p. 79-89.

BOURDIEU, Pierre.; PASSERON, Jean-Claude. Os herdeiros: os estudantes e a cultura. Florianópolis: Editora da UFSC, 2014.

CENTRO DE GESTÃo E ESTUDOS ESTRATÉGICOS. Doutores 2010: Estudos da demografia da base técnico-científica brasileira. Brasília: Centro de Gestão e Estudos Estratégicos, 2010.

LAHIRE, Bernard. Sucesso escolar nos meios populares: as razões do improvável, São Paulo: Ática, 1997.

NOGUEIRA, Claudio Marques Martins; NOGUEIRA, Maria Alice. A sociologia da educação de Pierre Bourdieu: limites e contribuições. Educação e Sociedade, Campinas, v. 23, n. 78, p. 15-36, abr. 2002. 
NOGUEIRA, Claudio Marques Martins; NOGUEIRA, Maria Alice. Os Herdeiros: fundamentos para uma sociologia do ensino superior. Educação e Sociedade, Campinas, v. 36, n. 130 , p. 47-62, 2015.

NOGUEIRA, Maria Alice. Convertidos e oblatos: um exame da relação classes médias/escola na obra de Pierre Bourdieu. Educação, sociedade e cultura: [s.n.], 1997. p. 109-129.

OLIVEIRA, Melina Del’Arco de; MELO-SILVA, Lucy Leal. Estudantes universitários: a influência das variáveis socio-econômicas e culturais na carreira. Psicologia Escolar e Educacional, Campinas, v. 14, n. 1, p. 23-34, 2010.

OLIVEIRA, Maria Helena Mourão Alves de. Funções da leitura para estudantes de graduação. Psicologia Escolar e Educacional, Campinas, v. 1, n. 1, p. 61-68, 1996.

SETTON, Maria das Graças Jacinto. A teoria do habitus em Pierre Bourdieu: uma leitura contemporânea. Revista Brasileira de Educação, n. 20, p. 60-70, maio/ago., 2002.

SETTON, Maria das Graças Jacinto. Processos de socialização, práticas de cultura e legitimidade cultural. Estudos de Sociologia, Araraquara, v.15, n.28, p.19-35, 2010.

VIANA, Maria Jose Braga. Longevidade escolar em famílias de camadas populares: algumas condições de possibilidades. In: NOGUEIRA, Maria Alice; ROMANELLI; Geraldo, ZAGO, Nadir. Família e escola: trajetórias de escolarização em camadas médias e populares.

Petrópolis: Vozes, 2000. p. 45-60.

\section{Agradecimentos}

À Fundação de Amparo à Pesquisa do Estado de São Paulo - FAPESP.

\section{${ }^{\mathrm{i}}$ Sobre as autoras}

\section{Maisa Aparecida de Oliveira}

E-mail: maisavrb@ hotmail.com / ORCID: http://orcid.org/0000-0001-8885-2416

Universidade Federal de Viçosa - Brasil

Doutora em Educação pela Universidade Federal de São Carlos [UFSCar]

Maria Cristina da Silveira Galan Fernandes

E-mail: mcsgfernandes@gmail.com / ORCID: http://orcid.org/0000-0002-8415-9400

Universidade Federal de São Carlos - Brasil

Doutora em Educação pela Universidade Estadual Paulista [UNESP] 